\title{
Agent-Based Approach for Interbank Liquidity Issue
}

\author{
I. Lucas, N. Schomberg, and V. Turpyn
}

\begin{abstract}
The succession of financial crisis in last decades has refocused the debate on banking regulation approach. Furthermore, recent crisis has highlighted the importance of "systemic risks" and especially, the leading role of institutions interconnectedness. In order to better understand how banks individual decision rules impact interbank market and how global Central Banks decision could impact individual liquidity position of institutions this paper provides a method with an agent-based approach to model interbank market and its liquidity issues. The agent-based model is marked by a set of behavioral descriptions related to daily interbank cash flows and refinancing process composed by two channels: lending, assets trading and loans selling. Applied to the European interbank network, different scenarios analyzed how individual decision rules impact on system's stability.
\end{abstract}

Index Terms - Systemic risk, financial contagion, liquidity risk, interbank market, agent based model.

\section{INTRODUCTION}

The last financial crisis has highlighted the importance of controlling systemic feature of interbank markets. Many papers deliberate how and who could improve banking system stability such as Gersbach and Wenzelburger [1], who discuss government involving in banking regulation or Greenspan [2] who affirms that it is central banks responsibility to "use its authority and expertise to forestall financial crisis (including systemic disturbances in the banking system) and to manage such crisis once they occur".

In Ref. [3] Elsinger and Lehar point out that there are two main sources of contagion during banking crisis: banks default which causes domino effect (intrinsic interbank contagion) and economy shocks which affect simultaneous multiple banks defaults (exogenous contagion source). Furthermore domino effect can be divided into two steps: first institutions default which will lead to systemic move and then banks default caused by the contagion of first failure. Several authors have highlighted the fact that it is only a node of few institutions which originally trigger systemic wave in banking crisis [4] and these institutions qualified as systemic are the core of actual banking regulation. Before future crisis, if not avoidable, it is needed to understand how to consolidate banking system for controlling contagion. That is why it seems interesting to develop a framework based on an agent-based approach which could analyze interbank network response to different liquidity management

Manuscript received May 25, 2014; revised July 22, 2014

I. Lucas and V. Turpyn are with the Financial Engineering Department, ECE Paris 37 quai de grenelle, Paris, France (e-mail: iris.lucas75@mail.com).

N. Schomberg is with the Information System Department, ECE Paris 37 quai de grenelle, Paris, France (e-mail: schomber@ece.fr). scenarios through individual decision rules. Besides, it is also possible to study what individual decision rules not only improve interbank liquidity management but also reduce the implicated degree of contagion.

In most papers [5], [6] liquidity requirements and cash flows of agents are randomly generated. Present situation is different: agents are represented by simplified balance sheet build from actual data and during each period of simulation the liquidity position is computed with regard to previous undertaken commitment by banks. In this way agent liquidity requirements are not random but sequentially depend on previous agent choices. And it is only through autonomous individual behaviors that it is possible to analyze how individual decision rules can impact on system stability.

The paper is organized as follows. After presenting the model, Section III provides simulation results. First some basic dynamics of studied scenarios are shown from graphical displays out of simulation in Section III. In Section III the different Investment Policy scenarios are discussed. Conclusion is given in Section IV.

\section{MODEL}

Unlike most papers on banking system where banks are not differentiated, it is supposed here that interbank system can be described by two parts:

- The core of network represents the largest and most systemic institutions or to put the matter differently their failure can individually turn into system wide failure.

- The periphery of network founded with medium and small banks whose individual failure could not directly impact on network. In this class, it is not interesting to analyze individual behavior, but instead to focus with larger-scale on a set of these banks which altogether could create enough perturbation to affect banking system.

In this way, it has been chosen to represent agents belonging to core by actual data extracted from balance sheets of active banks in interbank market (here European one has been chosen), and to generate fictitious and unique balance sheets for the other agents ${ }^{1}$.

All agents are represented by following simplified balance sheet, see Table I.

TABLE I: SIMPLIFIED BANKS BALANCE SHEET

\begin{tabular}{|c|c|}
\hline Assets & Liabilities \\
\hline Securities $S(t)$ & Deposit $D(t)$ \\
\hline Loans $I(t)$ & Borrowings $B(t)$ \\
\hline $\operatorname{Cash} M(t)$ & Equity $V(t)$ \\
\hline
\end{tabular}

${ }^{1}$ Fictitious balance sheets are simulated from aggregate values obtain upon the extrapolation of actual data. 
Three kinds of security $S(t)$ are considered: free risk $S_{f r}(t)$ hybrid $S_{h}(t)$ and risky $S_{r}(t)$. All of them present different market risk exposures and so they are remunerated in accordance with. Furthermore, it is assumed that a risky asset which needs to be sold immediately will be sold at $60 \%$ of its facial value; a hybrid security will be sold at $80 \%$ and a free-risk asset at $100 \%$.

Loans $I(t)$ contains both interbank loans $I_{i}(t)$ and customer loans $I_{c}(t)$. Interbank loans are dynamically represented throughout simulation whereas customer loans are supposed to be a random variable remunerated to a rate close to rate for housing loans. Borrowings $B(t)$ are only borrowings contracted on interbank market and deposit represents households saving. Equity $V(t)$ is only increased by provision for risk, which means $8 \%$ of nominal value for granted loan or $8 \%$ of total value of bought securities. Finally, cash $M(t)$ is inherited cash from previous period plus intra period cash flows and is represented available liquidity (or liquidity deficit).

In order to differentiate individual behavior, agents are categorized by three different strategies. These strategies reflect agent appreciation of liquidity with regard to gain. Agents called "risk free" mainly invest in riskless assets and prefer lend at short term, agents "hybrid" diversify their portfolio and attempt to balance both short and middle term loans whereas "risky" agents focus their investment on risky but high yield assets and are presumed to be less hesitant to lend on long term².

Besides their inter-period liquidity position, agents take into account another variable before taking decision: their overall liquidity trend $P(t)$. It consists in a weighted factor over last three available liquidities, the expected available liquidities at $\mathrm{t}$, and next three ones in such a way that:

$$
P(t)=\sum_{i=-3}^{3} a_{i} M(t-i)
$$

With weights $\sum_{1}^{3} a_{i}=\sum_{-3}^{-1} a_{i}=0.25 ; a_{0}=0.5$.

For this, several functions have been implemented to forecast agent expected liquidities in the next three periods. The calculation is based on the hypothesis that agents can forecast their monthly deposit variation to about $10 \%$. Furthermore, one can know the expected perceived interest and reimbursed nominal for all agents, and to precise the value of $P(t)$ one looks at previous balance sheet variations. Indeed, one computes for each agent how much, on average, its securities item or its interbank loans have increased or decreased according to whether the agent was liquid or illiquid.

$$
\begin{gathered}
\langle\partial S>=E[\partial S \mid G] \\
\langle\partial B>=E[\partial B \mid G] \\
\langle\partial I>=E[\partial I i \mid G]+E[\partial \mathrm{Ic}]
\end{gathered}
$$

where $G$ includes information related to liquidity position of agent and where $E[\partial \mathrm{Ic}]$ is the average of loans coming from

${ }^{2}$ Relatively in our model, the long term is assimilated to one year maturity commercial activity variation since the beginning of simulation.

From equations (2), (3) and (4) one can estimate next interests that agent will perceive or will lose resulting in expected securities, borrowings and interbank loans items variation, and so the expected liquidities:

$$
M t+i=M t+i-1+\langle\partial S\rangle \times R s+\langle\partial B\rangle \times R B+\langle\partial I c\rangle \times R I c
$$

With $i \in\{1,2,3\}$ and where $M t+i-1$ includes already-known cash flows. $R S, R B, R I C$ respectively correspond to securities yields, borrowings and loans rates. The process is iterated for each kind of tradable asset and each maturity of interbank loans.

Once $M(t)$ and $P(t)$ are computed, agents are associated to a liquidity state. The worst state is when $M(t)<0$ whatever the sign of $P(t)$ because the agent could only try to refinance itself and the agent is called "seeker". The stronger position is when both $M(t)$ and $P(t)$ are positive and the agent is declared as "investor". Finally, the intermediate state is when $M(t)>0$ and $P(t)<0$.Although fragile, the agent can invest again and holds "double-hatting" of seeker and investor.

\section{RESUlts}

In Ref. [7] it has been observed that differentiation of banks behavior due to strategies deeply impacts overall system stability. At this moment in the working process, the strategies mainly influence investment choices of the agents, and this is why it is important to determine if it is the nature of investment or the allocation between low-risk and high-risk securities which causes instability in the market. The studied scenarios here only impact the investment choices of agents which still have available liquidity at the end of period.

In [8] three scenarios have been analyzed in order to verify that the model does not present an unlikely underlying ideal scenario. These scenarios correspond to first case where banks would invest only in free-risk securities, to second case where agents survive only by investing in risky assets whose high yield permit them to buy liquidity at any cost and finally, and to last case where agents prefer to save their cash without investing. The results support the fact that not only banks need to invest for ensuring future liquidity and providing cash, but also that an exclusive free-risk investment does not permit them to obtain enough liquidity. Furthermore in [8] an (almost) ideal scenario has been presented, (also recalled below), highlighting the importance of proportionally relationship between low-risk financial asset ratios versus high-risk securities ratio as it has been deeply treated in [9].

The mentioned "almost-ideal" scenario above is inspired from the Value-at-Risk concept, and the situation is observed of what is happening when agents try to maintain a free-risk securities cushion whose value equals their worst illiquid scenario they have known since the beginning of simulation. For example, consider the agent "Société Générale" in one simulation at period 12. During this simulation and still period 12 , the worst liquidity deficit the agent has known has happened at period 5 and was equal to 20 Million Euros. However at period 12, the total riskless tradable assets value of Société Générale is equal to 18 Million Euros. To respect Cushion Investment Policy, the agent is going to buy the 
equivalent of 2 Million Euros of "free-risk" securities. Two cases of this scenario have been tested: the case where the Cushion Investment Policy is mandatory for all agents even if they have to indebt themselves to respect the constraint, and the case when there are only agents having the possibility to invest in cushion. In both two cases the Cushion Investment Policy is the only one that agents can adopt at the end of period. In order to compare results three assessment factors have been selected: the number of ejected agents before the end of simulation, the flows of changing states agents between two periods (how many liquid agents are becoming illiquid, vice versa and etc.) and how does such scenario costs to Central Bank.

With regard to scenarios presented in [8] and [9] and as shown on Fig. 1 and 2, the Cushion Investment scenario permits the network to reach a certain degree of stability. Indeed, in Fig. 1 it is observed(by recalculating with number of agents by class, and with a total of 600 agents in network) that $4.5 \%$ of agents have been ejected at the end of the simulation and in Fig. 2 that at the end of simulation more than $70 \%$ of agents stay liquid throughout all periods. Furthermore, with a share of invested liquidity by central banks equal to about $36 \%$ the cushion investment policy is also the less expensive for regulators (at the end of the simulation this value tend to be equal about to $17 \%$ ).

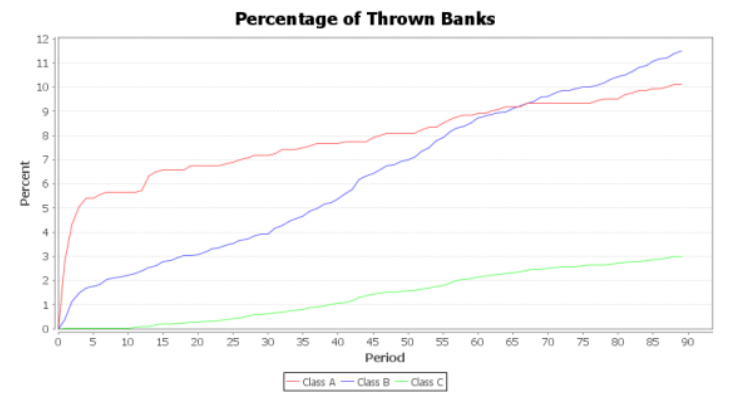

Fig. 1. Case "cushion investment" - percentage of ejected agents by class.

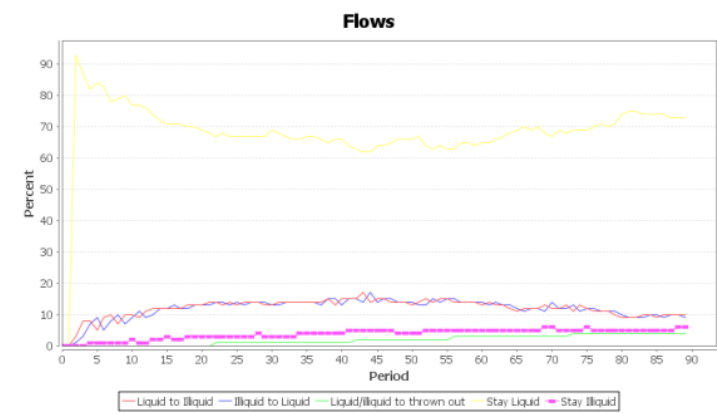

Fig. 2. Case "cushion investment" - flows of changing states agents between 2 periods.

Taking into account the fact that banks balance sheet tends to increase, it is interesting to base cushion value by reporting the worst liquidity deficit with regard to the total asset of agent. As shown in Fig. 3 and Fig. 4, in this way the scenario improves network state with about $3 \%$ of ejected agents before the end of simulation. Although this new calculation method for cushion value represents a slight improvement, it anyway highlights the rolet of counterparty risk. Indeed, when the value of cushion represents a percent of the total asset, it is not only the ensured agent that provides enough riskless securities in case where it needs to borrow from Central Bank, but also a part of potential doubtful claim.

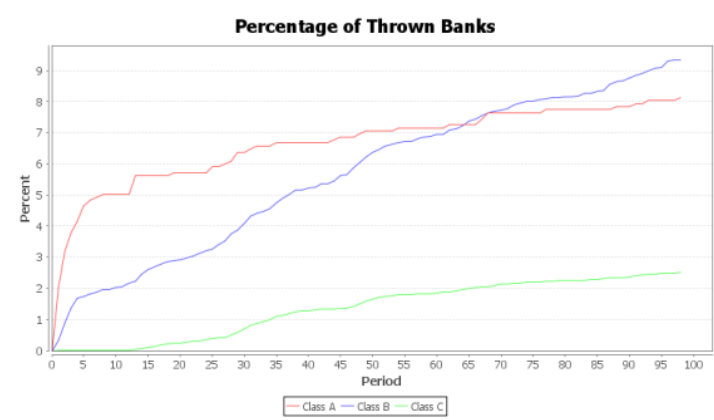

Fig. 3. Case "cushion investment bis"- percentage of ejected agents by class

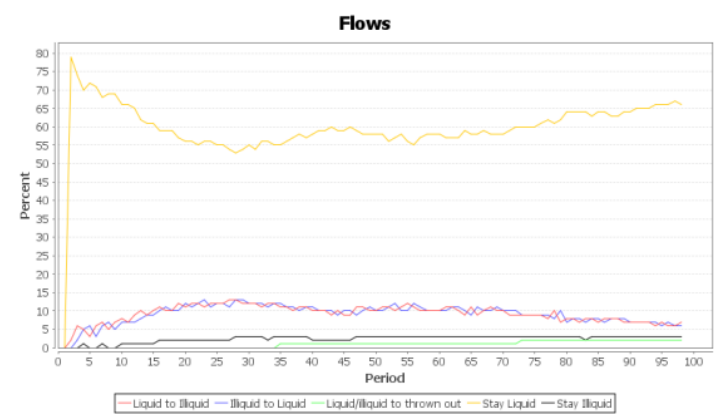

Fig. 4. Case "cushion investment bis" - flows of changing states agents between 2 periods.

The results of Cushion Investment scenario "bis" lead to consider future implementation of scoring process in order to test different scenarios related to calculation method of cushion value. The scoring will be a process to classify and to attribute a score (a mark) to an agent. The score will depend on adopted strategy $Z$, on inter-period ratio of liquidity $\rho_{L}$, on exposure mean $\rho_{e x}$, and on total of REPO borrowings contracted from Central Bank $B_{R E P O}(t)$.

The score will be set between 0 and 1, with "safest" bank shaving a score close to 1 and weakest banks a score close to 0 .

1) The inter-period ratio of liquidity $\rho_{L}$ is the weighted sum of past liquidity variation:

$$
\rho_{L}=\sum_{i=0}^{t} b_{i} \Delta M(t-i)
$$

with $\forall i, j, i<j ; b i>b j$

2) The exposure average $\rho_{e x}$ represents the aggregate value of loans nominal average with regard to the total asset:

$$
\rho_{e x}=\frac{I(t)}{A(t) \times n c}
$$

where $n_{C}$ is the number of counterparties

3) All scores are divided by highest score to get a distribution between 0 and 1 .

Score calculation will be defined as follows:

4) Score $S_{c}(t)$ has to increase with the intraperiod ratio of liquidity $\rho_{L}$

5) Score $S_{c}(t)$ has to decrease with the exposure mean $\rho_{e x}$

6) Score $S_{c}(t)$ is a decreasing function with total of REPO borrowings contracted from Central Bank $B_{R E P O}(t)$. Indeed, in the model if an agent conducted to borrow from Central Bank, this means that its liquidity deficit is too high for interbank market or interbank market is 
strongly illiquid. In both cases a high value of $B_{R E P O}(t)$. reflects a potential strong illiquid position.

7) Score $S_{c}(t)$ has to increase if the strategy is safe; for free risk strategy $z=1$, for hybrid strategy $z=1$ and for the risky strategy $z=2$.

Finally score expression will be:

$$
S_{c}(t)=\frac{\min \left(0, \frac{\rho_{L}}{\rho_{e x}+B_{R E P O}(t)^{+\mathrm{z}^{2}}}\right)}{\max \left(S_{c}^{1}(t), \ldots S_{c}^{i}(t), \ldots S_{c}^{N}(t)\right)}
$$

\section{CONCLUSION}

The paper presents a descriptive model of individual banking agent decision rules where refinancing process is autonomously managed by each agent throughout simulations, and investment process is driven by their preferences between liquidity and gain. In contrast to traditional models, present model is based on a blend of real and fictitious banking data obtained by splitting agents into two classes: strong systemic banks whose actual balance sheets are represented and a set of medium and small banks (whose individual failure will not cause system collapse) represented by fictitious data distributed around real average values.

In [8] a first version of first version of Cushion Investment Policy has been presented where the value of agent cushion was based on the value of worst liquidity deficit experienced by the agent. In [9] an extensive study related to relation between the share of low-risk securities and the ratio of risky financial assets has shown that this is a strong difference between agents ejected before the end of simulation and the surviving ones: ejected agents have a share of risky tradable assets largely higher than their ratio of low-risk securities, and the paper provides a first step in the quantification of ratio between risky and riskless tradable assets. However, it has been seen in Results Section that Cushion Investment Policy is better if the value of cushion is a percent of agent total assets. The main explanation behind this result is that cushion also covers a part of unexpected loss which could come from counter-parties defaults or any not repaid debt. This is why in a further research a scoring process will be implemented, and a reflection will be conducted about how to fit it into agents decision rules in a way to do not create strong new constraints leading to weaken more implemented network, and instead to help it to target the weakest agents and to develop adequate regulator policy in the model.

\section{ACKNOWLEDGMENT}

The authors are very much indebted to ECE Paris School of Engineering for having provided the environment where the work has been developed and Pr M. Cotsaftis for help in preparing the manuscript.

\section{REFERENCES}

[1] H. Gersbach and J. Wenzelburger, "The workout of banking crises: a macroeconomic perspective," CESifo Economic Studies, vol. 49, no. 2 , pp. $233-258,2003$.

[2] A. Greenspan, "The role of capital in optimal banking supervision and regulation," FRBNY Economic Policy Review, vol. 4, pp. 163-168, 1998.

[3] H. Elsinger, A. Lehar, and M. Summer, "Risk assessment for banking systems," Management Science, vol. 52, no. 9, pp. 1301-1314, 2006.

[4] E. B. Santos and R. Cont, "The brazilian interbank network structure and systemic risk," Working Papers Series, no. 219, 2010

[5] J. Bryant, "A model of reserves, bank runs, and deposit insurance," Journal of Banking \& Finance, vol. 4, no. 4, pp. 335-344, 1980.

[6] D. W. Diamond and P. H. Dybvig, "Bank runs, deposit insurance, and liquidity," The Journal of Political Economy, pp. 401-419, 1983.

[7] Lucas, "Agent based interbank network dynamics with individual bank interaction rules," in Proc. Intern. Conf. on Economics and Finance Research, Seoul, South Korea, April 12-13, 2014

[8] Lucas, S. Schomberg, and V. Turpyn, "Impact of individual Banking Agents' decision rules on interbank network," in Proc. Intern. Conf. on Business Research, the 5th Asia Business Research Conference, Kuala Lumpur, Malaysia, February 17-18, 2014.

[9] Lucas, "Agent based approach for banking investment ratios," in Proc. Intern. Conf. on the Finance, Global Management, Economics \& Information Technology Research Conference, New York, United States, May 22-25, 2014.

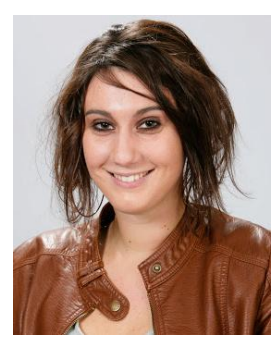

Iris Lucas entered ECE Paris School of Engineering in 2011 with specialization in financial engineering major during the second year after two years at University Paris Diderot in Paris to study physics and mathematics. Since then, I. Lucas has been working on model representation of interbank networks and in 2013, I. Lucas wrote in collaboration the two papers "Liquidity Risk Contagion in Interbank Networks" and "Impact of Liquidity Crunch on Interbank Network" which provide, through a dynamical agent-based model, analysis of liquidity crisis scenarios applied to European market case represented by a network of 600 real and fictitious banks. She also presented the paper "Confidence Crisis in Interbank Networks" on July 12, 2013 at the Society for Computational Economics for Computing in Economics and Finance Conference in Vancouver. I. Lucas has been further invited to deliver lectures on March 24, 2013 at European Institute of Financial Regulation (EIFR) in Paris, on July 2, 2013 at Organization for Economic Co-operation and Development (OECD) in Paris. She is now currently focusing her work on banking system robustness. 